\title{
Article \\ Are We Ready for Cyberlearning? A Study by Students, about Students, for College Leaders
}

\author{
Patricia Marybelle Davies ${ }^{1, t, *}\left(\mathbb{D}\right.$, Reem Muteb T. Alotaishan ${ }^{2, \ddagger}$, Hayat Khalid A. Alabdulwahed ${ }^{3, \ddagger}$, Ali M. Fahim \\ Khan ${ }^{4, \ddagger}$, Rawan Mohammad Ateya ${ }^{5, \ddagger}$, Thamer Saleh Alkhamis ${ }^{4, \ddagger}$ and Abdulaziz Abdullah A. Alodhieb 5

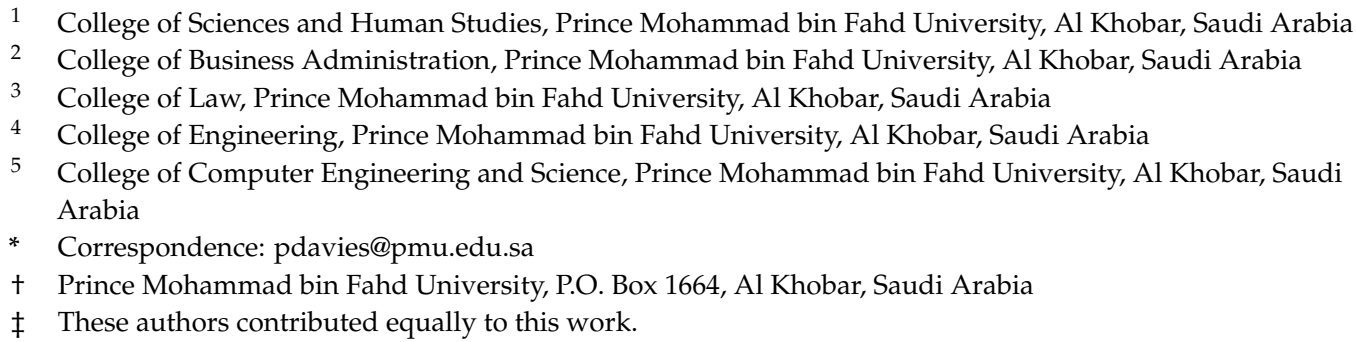

check for

updates

Citation: Davies, P.; Alotaishan, R. M T; Alabdulwahed, H.; Khan, A.;

Ateya, R. M. Alkhamis, T.; Alodhieb, A. Are We Ready for Cyberlearning? A Study by Students, about Students, for College Leaders. Preprints 2022, 1, 0. https://doi.org/

Publisher's Note: MDPI stays neutral with regard to jurisdictional claims in published maps and institutional affiliations.

Copyright: (C) 2022 by the authors. Licensee MDPI, Basel, Switzerland. This article is an open access article distributed under the terms and conditions of the Creative Commons Attribution (CC BY) license (https:// creativecommons.org/licenses/by/ $4.0 /)$.

\begin{abstract}
Many assumptions exist about online learning and its impact on college students. Hitherto, the views of those meant to be the beneficiaries of this technology have been given little consideration despite the fact that students use cyberspace for academic work and beyond. This qualitative casestudy report is based on research conducted by college students at a private university in the Eastern Province of Saudi Arabia. The aim was to examine the online learning experiences of their peers during the first wave of the coronavirus global pandemic, with a view to understand how prepared their university is for an academic genre located in cyberspace. The findings are based on the perspectives of 2,298 college students responding to a survey administered to the entire student population comprising around 9,000 individuals. They suggest that increasing opportunities for cyberlearning could have positive effects on students. Also provided is cautionary advice about the need to improve teaching pedagogies and combat academic dishonesty.
\end{abstract}

Keywords: cyberlearning; educational innovation; higher education; online learning; student voice

\section{Introduction}

This paper reports on research examining students' perceptions of cyberlearning at one university in Saudi Arabia. The study was conducted by a group of student-researchers to understand the online learning experiences of their peers during the unprecedented move to online education due to the global COVID-19 pandemic. They explore, analyze and describe data collected through an empirical survey. The primary questions guiding the research is, what were the online learning experiences of students at our university, including us, during the first two semesters of lockdown? The research goes further to examine whether or not participants view cyberlearning as distinct from online learning, and how prepared these students feel they and the institution are for this emerging educational approach.

The impetus for this work lies in the observation that since the introduction of computers into academia over three decades ago, the voices of those intended to be the beneficiaries of digital technologies have to a large extent remained silent [1]. Much of the current setup has relied on the views of proxy informants such as instructors, technology directors and institutional heads. What is distinctive about this study is that it provides the first-hand accounts of college students who report on their experiences with online education at a time when they had no alternative. Also, that the researcher is conducted by students and is about students' experiences.

Current demands on Higher Education Institutions (HEIs) to equip students for life in the knowledge-based, self-service, digital culture of the 21st century now make it necessary to turn the spotlight on the primary users of technology-students themselves. Students spend much of their time in cyberspace and there is much to be garnered from them about 
their experiences of learning online. Their critiques and analysis can be both constructive and non-oppositional. Furthermore, democratic notions of representation and participation as members of their academic communities make it necessary to involve them in the debate on online learning. The global pandemic presented a crisis which challenged the old ways of doing things, raising new questions about our system of education. Some academics claim that nothing since the Second World War has had a more disruptive impact on education. For many students, lockdown was a wake-up call to the reality that online learning can no longer be seen as a separate category; instead, nearly all learning activities must now include a technology component.

According to the National Science Foundation (NSF), cyberlearning is supporting learning through the use of networked computers and communications technologies [2]. Cyberlearning research is now of paramount interest worldwide, especially with respect to the future of student learning. Hitherto, there have been many variations in the scope and understandings of this new learning paradigm. These disagreements pose problems for HEIs interested in promoting cyberlearning practices and have led to differences in opinions about the purposes of cyberlearning in education. Furthermore, it highlights the need for an educational public space in which to reflect collectively and consider possible ways forward with learning technologies.

\section{Overview of the Study}

\subsection{The Purpose}

This qualitative study aimed to collect, analyze, and describe students' experiences of online learning at the case study institution. Through an examination of students' online learning experiences it sought to gather information about what works and what needs improvement. Such information could help institutional leaders validate the massive technology investments that have been made over the past 18 months.

Missing from the growing body of research about education through and beyond the pandemic is evaluative data obtained from students on their online learning experiences. As learners in the digital age, students' perspective on learning is unique. Therefore, it is important to have them contribute to such discussions. Over the past 2 years, many institutions have spent considerable amounts of money on improving students' experiences in the online world. New learning platforms, new software and hardware, instead of conducting research to evaluate these options. On the whole, HEIs now have a better understanding of the benefits of educational technology than they did before the pandemic, and are more willing to involve students in helping them understand what online tools students use. This research followed a successful funding award by the student researcher from their institution.

\subsection{The Setting}

The setting for the present study is in a private university located in the Eastern Provence of the Kingdom of Saudi Arabia. With an undergraduate student body of just under 9,000, the university has two distinct campuses in adjoining locations-one for male students and the other for female students. Most come from the Eastern Province of the country and are all day students. The survey was created by six undergraduate student researchers, three male and three female-sophomores to seniors-with majors in Computer Science, Engineering, Finance, and Law. This multi-faceted team work jointly with the faculty supervisor facilitating the research. The study is a first phase of an action research project examining the potential for cyberlearning at the institution.

\subsection{The Methodology}

A qualitative approach is the best way to preserve the uniqueness of students' perspectives on online learning, and makes it possible for the action research to develop gradually. One of the greatest strengths of qualitative research is that it produces dense, natural, narrative descriptions and so they cannot be neatly pigeon-holed and reduced to a simple 
and prescriptive set of principles [3]. The study took place on site, in the group's natural environment, and attempts to be non-manipulative of group behavior. The purpose is to aim for objectivity while taking into account the views of the participants, thereby limiting the biases of the researcher.

\subsection{The Survey}

The survey instrument designed by the undergraduate researchers first explored the demographics of the participants: gender, major, college level and year of admission. Respondents were also asked to report on three aspects of their online classes: the learning technologies, instructional approaches and assessment formats utilised by their instructors in these core curriculum areas-mathematics, science and humanities-studied by almost all students at the university. Table 1 shows the reporting options in these areas.

Table 1. Reporting Categories in the Survey.

\begin{tabular}{|c|c|c|}
\hline Learning Technologies & Instructional Approaches & Assessment Formats \\
\hline $\begin{array}{l}\text { PowerPoint or other } \\
\text { presentation slides }\end{array}$ & $\begin{array}{l}\text { Lecture: the instructor talked } \\
\text { and we listened }\end{array}$ & $\begin{array}{l}\text { Comprehension: read and } \\
\text { answer questions }\end{array}$ \\
\hline Whiteboard in Blackboard & $\begin{array}{l}\text { Q \& A: the instructor asked } \\
\text { questions and we answered }\end{array}$ & $\begin{array}{l}\text { Discovery: look up } \\
\text { information }\end{array}$ \\
\hline Graphics Tablet & $\begin{array}{l}\text { Quiz: we were quizzed during } \\
\text { the lecture }\end{array}$ & $\begin{array}{l}\text { Researching: gather and } \\
\text { analyze data }\end{array}$ \\
\hline Quiz facility in Blackboard & $\begin{array}{l}\text { Discussion: we discussed the } \\
\text { material with our classmates }\end{array}$ & $\begin{array}{l}\text { Construction: create products } \\
\text { such as reports and } \\
\text { presentations }\end{array}$ \\
\hline $\begin{array}{l}\text { Break-Out Rooms in } \\
\text { Blackboard }\end{array}$ & & $\begin{array}{l}\text { Collaboration: work with } \\
\text { others }\end{array}$ \\
\hline & & Lab work \\
\hline
\end{tabular}

Each of these categories was applied to the aforementioned subjects. Included as an option under each of these categories was Not Applicable, which a student could choose if the student did not take that particular course. Other items in the survey asked participants about their motivations for and their opinion of learning online via the institution's platform. Another section of the survey provided a video which was used to check what participants understood by cyberlearning. The final section of the questionnaire examined participants' aspirations for cyberlearning at the institution. They were also asked to score the institutions preparedness on a scale of 1 to 5 . In preparations for the next phase of the action research project, the survey was also used to solicit participation in a student-led Focus Group on cyberlearning.

\section{Results and Discussions}

The survey data were both quantitative and qualitative. This section discusses the survey results and provides some early interpretation that can be drawn from them.

\subsection{Demography}

Almost $80 \%$ of the 2298 students who attempted the survey were male. One explanation of this skewness might be cultural. Originally limited to male students, HEIs in Saudi Arabia first enrolled Women in 1962 through an off-campus program called ENTSAB [4]. Recent data on gender distribution shows that over $55 \%$ of students graduating from universities in KSA are female [5]. However, women remain reserved in sharing their views due to prevalent cultural norms, especially in the Eastern Province. The survey respondents were distributed across all the faculties within the university. Over $70 \%$ of them were freshmen and sophomores. 


\subsection{Learning Technologies}

Analysis of the survey data revealed that most instructors in the three core curriculum areas-mathematics, science and humanities-mainly used PowerPoint or other slides for teaching online classes. The second most commonly used learning technology in the online sessions was the Whiteboard facility in Blackboard. The exception was the humanities where instructors used the quiz facility and graphics tablets more frequently than the Whiteboard. Most significant was the use of a single instructional approach by some instructors in the humanities who only used presentations slides. This was unlike instruction in mathematics and sciences which showed a more varied use of digital technologies. Figure 1 shows the survey results by percentage use of learning technologies for courses in the humanities.

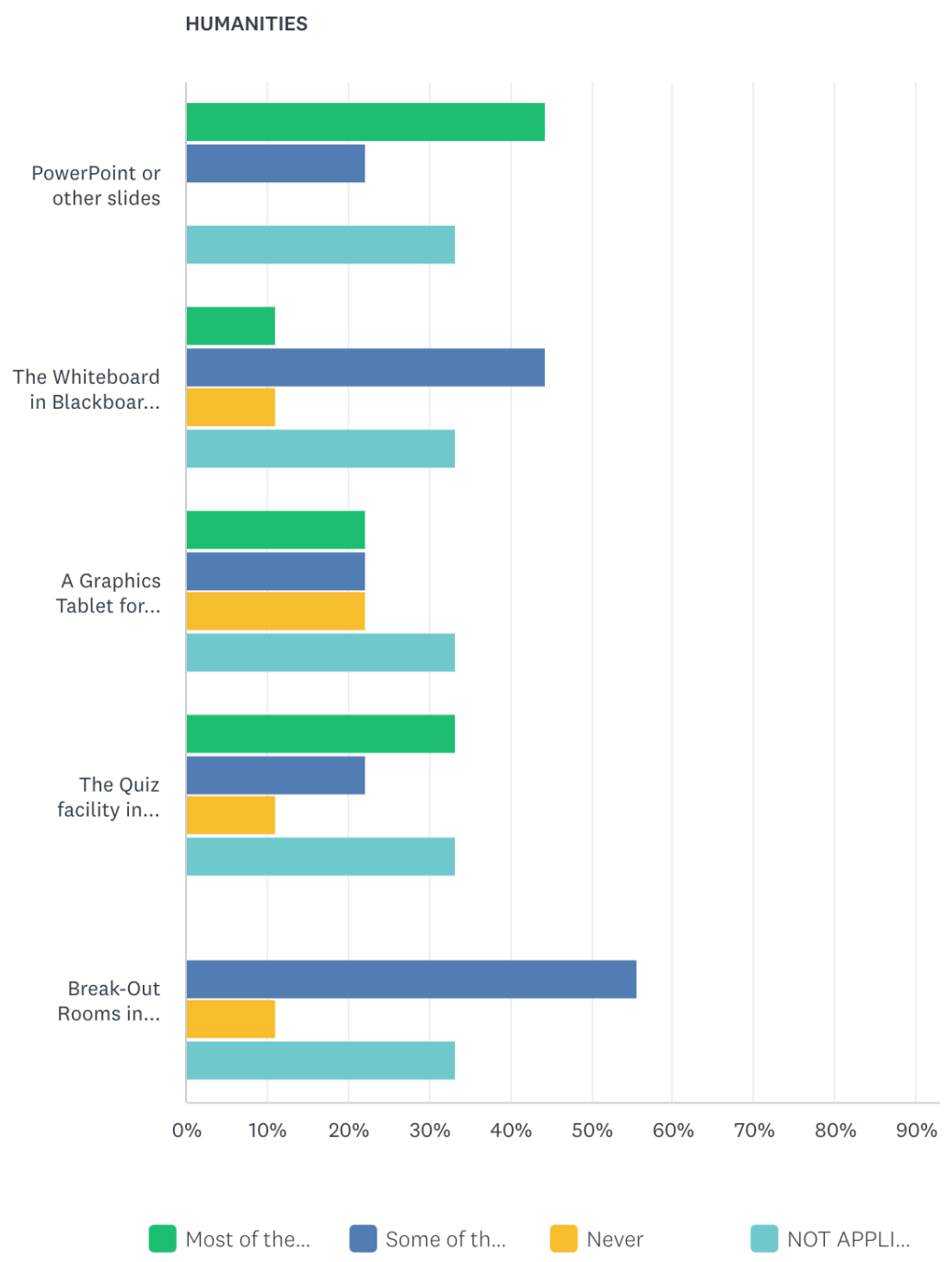

Figure 1. Results for Learning Technologies used by humanities instructors.

\subsection{Instructional Approaches}

Figure 2 shows the survey results by percentage use of instructional approaches used for teaching mathematics courses. In all three subjects, respondents reported that a lecture style was predominantly used. This involved the instructor delivering information by talking to the class, with or without any form of shared text. Question and Answer, Quizzes and Discussions were most commonly used in addition to lectures by mathematics instructors. There were instructors in all three curriculum areas who never used quizzes nor discussions. 


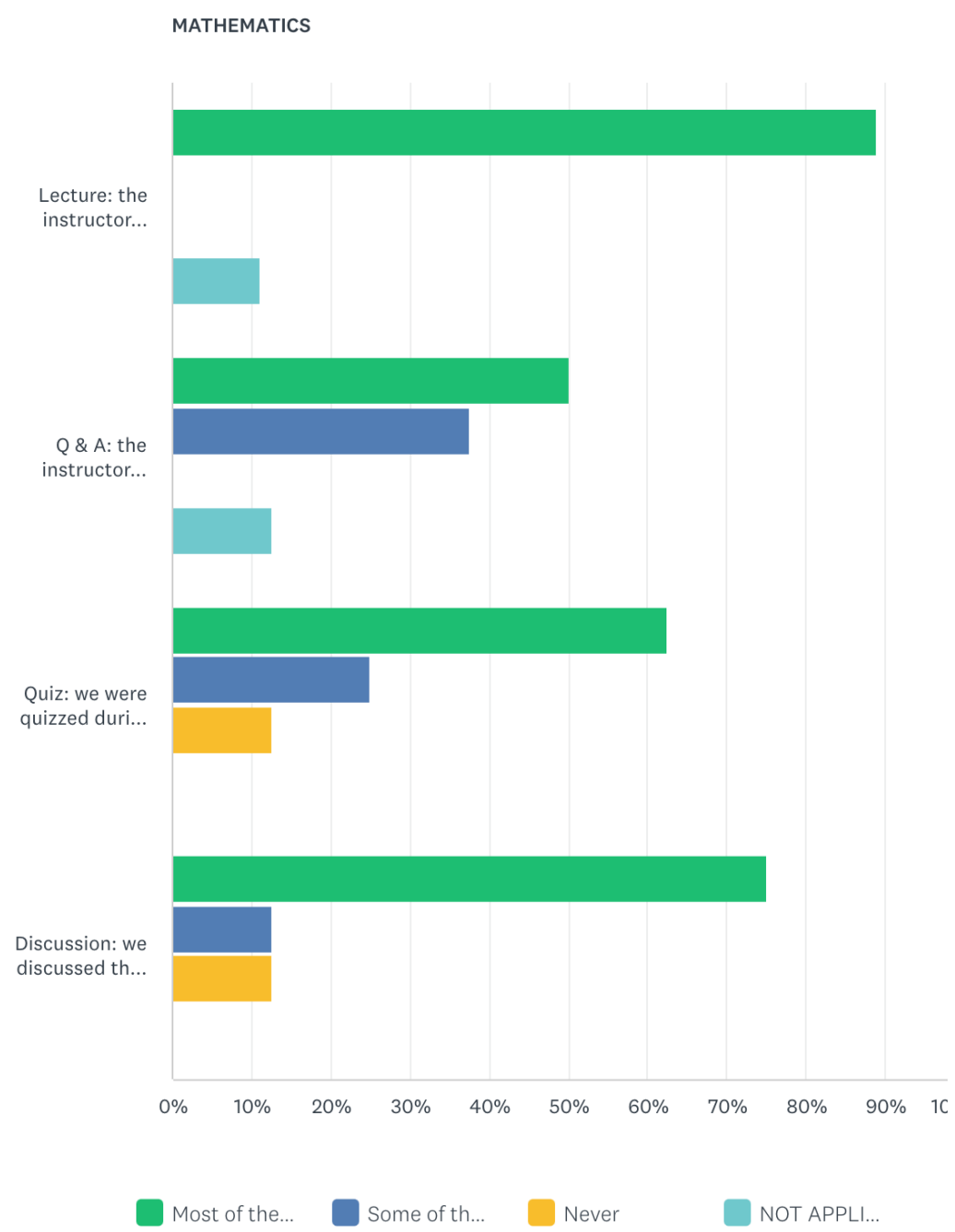

Figure 2. Results for Instructional Approaches used by mathematics instructors.

\subsection{Assessment Formats}

The most variety in assignment formats was reported in the humanities. In this category, students reported doing tasks involving collaboration, comprehension, construction, discovery, and research. The majority of respondents reported that most of their assignments in science-related subjects involved lab work. This was not surprising since all lab sessions were mandatorily conducted in-person on campus.

Further analysis of the survey information revealed that the predominant pattern of online instruction across all three subject areas was delivering information, whereby students are presented the course content often using PowerPoint or a similar application. Such an approach is discussed elsewhere [6] as the prevalent use of technology when teaching in-person classes. Having online teaching mirror what is typically done during in-person sessions indicates the need for new online pedagogies that allow for more interactions and more independent contributions by students in cyberclassrooms.

\subsection{Perspectives on Cyberlearning}

Respondents were asked to define cyberlearning. These questions were meant to serve as a catalyst for increasing their understanding of the field. The following statements were provided as prompts. Figure 3 shows the results of how the respondents view cyberlearning. 
1. Cyberlearning is the same as Virtual or Online Learning because both use electronic tools to facilitate learning;

2. Cyberlearning extends Online Learning by using technology to facilitate learning experiences that make it possible for learners to play a more active role in understanding concepts;

3. Cyberlearning is learning by searching the Internet for information.

4. Cyberlearning involves using new and developing technologies to create active learning experiences.

5. Cyberlearning investigates the future of learning with technology.

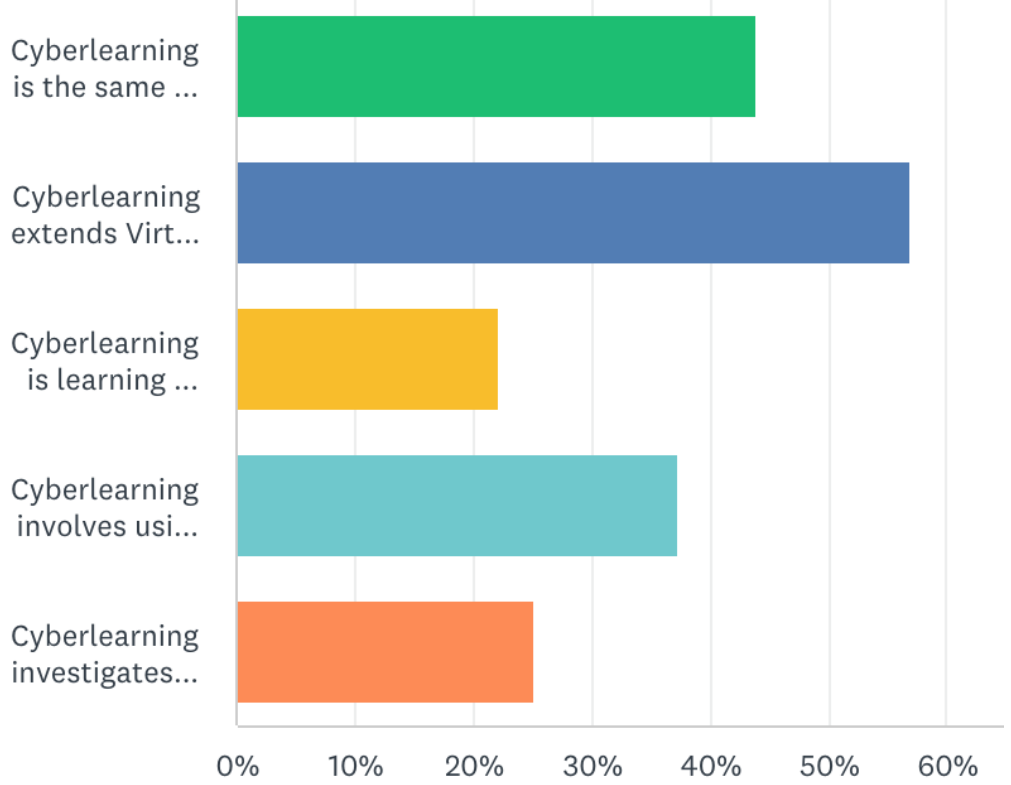

Figure 3. Respondents' views of cyberlearning.

These results show that almost $50 \%$ of the participants in the survey view cyberlearning as being the same as online learning. Even though both make use of similar digital tools, some respondents are unaware of the important differences between these two modes of learning in cyberspace. Successful online learning depends on the self-motivation of individuals, whereas cyberlearning technologies are designed to motivate and have an impact on how and what people learn. Notably, the latter is underpinned by continuing research. Cyberlearning requires more active participation by the learner who is self-driven to engage with the technology. Researchers in the field are concerned with developing technologies that help students use their minds and bodies to collaborate, think creatively and engage with new ideas in the digital world. There is also some focus on advancing computer technology in ways increase learning experiences, as well as, expanding access and equity to extend learning opportunities to all [7].

\subsection{Aspirations for Cyberlearning}

There is litte doubt that most participants were very excited about prospects to learn in new ways. Almost $80 \%$ of them reported being highly motivated by their online learning experience. When asked to elaborate on their responses, some students commented that learning online was safer and more convenient than having to travel to campus during a time of uncertainty and made them feel less anxious about participating in class. Many more relished the opportunity to watch recordings of their lectures over again.

The average rating score for the amount of cyberlearning at the institution was 4.7 out of 5 , with an overwhelming $90 \%$ of respondents claiming they feel the institution is 
ready for 'cyberlearning'. For the purposes of our analysis we took this to mean online learning. Some comments provided by the respondents showed that their score was based on comparing the online provisions made by other universities in the region with theirs. Most participants agreed strongly that more 'cyberlearning' opportunities would be beneficial, with one stating that "some lectures/lessons/classes don't need traditional learning, because some of them can be extremely short to the point".

\subsection{Problems with Implementing Cyberlearning}

Students cited the attributes of convenience and ease of participation as the foremost advantages of online learning. However, they were also aware of the formidable challenges this genre of learning presents. Two recurring reasons for concern given by respondents in the commentary were instructor preparedness and academic dishonesty.

Many students questioned how much training instructors had to teach online and their experience thereof. One student claimed that one instructor only gave 'audio lectures' and never shared the teaching presentation. Designing online course effectively is a great responsibility for instructors. It is not enough to simply put the same content utilised during in-person courses on screen and expect it to work. Unlike the three-dimensional world of the campus classroom, the cyber classroom is two-dimensional. Therefore, it is necessary for instructors to learn how to facilitate and assess learning online. The need for instructors to be prepared to teach online brings to bear the issue of time. Significantly higher amounts of time are needed in preparing to teach online than in-person. This issue will be explored further in the instructor survey which follows in the second cycle of the action-research project.

Respondents also reported witnessing two distinct forms of academic dishonesty. The first involved students getting answers from elsewhere, either from a text-physical or web-based-or from someone else. The second was through the learning platform itself when an instructor failed to put in place the correct security measures to prevent students from accessing the answers provided for autoscoring.

One of the biggest barriers to adopting online education is academic dishonesty. There are now many options available for impeding students from using unsavoury approaches for completing assessments, but students still find ways to get the grade they want without earning it. In fact, academic brokering, whereby another person is paid to complete assignments, or even take the course for the student, has been exacerbated by the Internet.

A strong case for cyberlearning is that it shifts the focus from assessment to engagement. For example, having students grapple with the data produced during learning activities based on embodied computing, while working in groups, helps nurture selfworth and develops their confidence as creators of knowledge. On the other hand, a teaching approach in which the instructor continuously delivers information to students does little more than create an overdependence on knowledge being handed down.

\section{Conclusions}

The information provided by respondents about what works and what doesn't with regards to online learning is worthy of serious consideration by institutional leaders. Studying though the COVID-19 era has giving them unique perspectives on what constitutes learning in a virtual world. Regardless of whether or not these students fully comprehend cyberlearning one messages is clear, they are ready for a new genre of education that involves the cyberworld, a space in which they already live, work and play. Therefore, the onus is now on educators to redesign education so that students are not simply preoccupied with finding ways to game the system. A 21st Century approach focused on bring out the best in students instead of being focused on attempting to measure, often unsuccessfully, how good or bad they are. An approach which raises the status of students within their institutions.

Author Contributions: Conceptualization, P.D.; methodology, P.D.; software, P.D.; validation, R.M.T.A., H.A. and A.K.; formal analysis, P.D.; investigation, P.D., R.M.T.A., H.A., R.M.A., A.K., T.A. 
and A.A.; resources, P.D.; data curation, P.D.; writing-original draft preparation, P.D.; writingreview and editing, R.M.T.A., H.A. and A.K.; visualization, P.D.; supervision, P.D.; project administration, P.D.; funding acquisition, H.A., T.A., R.M.A., A.K. and A.A. All authors have read and agreed to the published version of the manuscript.

Funding: This research was funded by the Prince Mohammad bin Fahd Center for Futuristic Studies in association with the World Futures Studies Federation through the PMFCFS Second Futures Research Grant.

Institutional Review Board Statement: This study is an educational issue and does not involve human experiments. Data were collected through an anonymous online questionnaire. The study follows the Ethical Guidelines for Educational Research, fourth edition (2018) produced by the British Educational Research Association.

Informed Consent Statement: Informed consent was obtained from all subjects involved in the study.

Data Availability Statement: Data sharing is not applicable to this article.

Conflicts of Interest: The authors declare no conflict of interest. The funders had no role in the design of the study; in the collection, analyses, or interpretation of data; in the writing of the manuscript, or in the decision to publish the results.

\section{References}

1. Sant, E. Democratic education: A theoretical review (2006-2017). Review of Educational Research 2019, 89, 655-696.

2. Borgman, C. L.; Abelson, H; Dirks, L.; Johnson, R.; Koedinger, K. R.; Linn, M. C.; Lynch, C. A.; Oblinger, D. G.; Pea, R. D.; Salen, K.; Smith, M. S.; Szalay, A. Fostering Learning in the Networked World: The Cyberlearning Opportunity and Challenge. A 21st Century Agenda for the National Science Foundation, UCLA: Center for Knowledge Infrastructures, 2008 [Report of the NSF Task Force on Cyberlearning, No. nsf08204, p. 59, 2008].

3. Mason, J. Qualitative researching, 3rd ed.; Publisher: Sage London, UK, 2017.

4. Al Alhareth, Y.; Al Dighrir, I.; Al Alhareth, Y. Review of Women's Higher Education in Saudi Arabia. American Journal of Educational Research 2015, 3, 10-15.

5. Share of female graduates in Saudi Arabia from 2010 to 2019. Available online: https://www.statista.com/ (accessed on 22 February 2022).

6. Davies, P. M. Student participation in school ICT policy-making: a case of students as researchers. Management in Education 2011, $25,71-77$.

7. Roschelle, J.; Martin, W.; Ahn, J.; Schank, P. Cyberlearning community report: The state of cyberlearning and the future of learning with technology; Publisher: SRI International, Menlo Park, California, USA, 2017. 